\title{
School performance in children with type 1 diabetes- a population-based register study
}

\author{
G. Dahlquist • B. Källén • \\ On behalf of the Swedish Childhood Diabetes Study \\ Group
}

Received: 22 November 2006 / Accepted: 12 January 2007 / Published online: 27 February 2007

(C) Springer-Verlag 2007

\begin{abstract}
Aims/hypothesis We examined the school marks of diabetic children in Sweden at the time of leaving compulsory education. Marks were examined in comparison with nondiabetic children and with special regard to age at onset of diabetes.

Subjects and methods The study involved 5,159 children who developed diabetes between 1 July 1977 and 1 July 2000, and 1,330,968 non-diabetic children. We linked the nationwide Swedish Childhood Diabetes Register to the Swedish School-Mark Register, which contains school marks for all children in Sweden at the time of leaving compulsory education (usually at 16 years old). Adjustment was made for potential confounders such as year of birth, maternal age, parity and educational level.

Results The mean of all numerical school marks for diabetic children was slightly but statistically significantly lower than those of the referent children $(3.15 \pm 0.01$ [mean $+\mathrm{SD}]$ vs $3.23, p<0.001)$. The lowest mean score was among children with diabetes diagnosis before the age of 2 years $(2.97 \pm 0.09$ vs $3.08-3.17$ in the older age groups, $p=0.10$ ). When individual subjects were studied (sports, mathematics, English and Swedish), a more complex picture emerged. In
\end{abstract}

Swedish Childhood Diabetes Study Group: for list of participants in this group, see the Electronic supplementary material.

Electronic supplementary material The online version of this article (doi:10.1007/s00125-007-0615-2) contains supplementary material, which is available to authorized users.

G. Dahlquist ( $\bowtie)$

Department of Clinical Sciences, Paediatrics, Umeå University,

90185 Umeå, Sweden

e-mail: gisela.dahlquist@pediatri.umu.se

B. Källén

Tornblad Institute, Lund University,

Lund, Sweden four subjects (mathematics, English, Swedish and sports) the risk of a diabetic child not getting a school mark or not passing was increased; in sports and English the diabetic children had significantly reduced odds of getting a high mark.

Conclusions/interpretation Despite a well-developed diabetes care system, we have not succeeded in preventing the disease from affecting school achievements. Among children with a young age at onset and therefore longer duration, the negative effects tend to be greater.

Keywords Age of onset - Children · Gender .

School performance $\cdot$ Sex $\cdot$ Type 1 diabetes

\author{
Abbreviations \\ DCCT Diabetes Control and Complications Trial \\ MBR Medical Birth Register \\ OR odds ratio \\ SCDR Swedish Childhood Diabetes Register
}

\section{Introduction}

Over the past few years, the efforts to improve metabolic control in childhood diabetes have probably contributed to the decreasing prevalence of diabetic complications [1-3]. Particularly since the strong proof provided by the Diabetes Control and Complications Trial (DCCT) [4], attempts to keep $\mathrm{HbA}_{1 \mathrm{c}}$ below the proposed threshold value have been adopted by most clinicians, including those in paediatric clinics, especially as it has been shown that, as early as in the first years of type 1 diabetes, metabolic control has an impact on markers of late complications $[5,6]$. Strict metabolic control, however, has always been controversial in children due to the risk of hypoglycaemia and its potentially more dangerous consequences, especially in 
young children [7, 8]. The DCCT applicability for childhood-onset cases has therefore been discussed $[9,10]$ and the incidence of hypoglycaemia in childhood diabetes has been shown to have increased over the past decade [11]. The reduction of $\mathrm{HbA}_{1 \mathrm{c}}$ using intense insulin treatment regimens with simultaneous avoidance of frequent hypoglycaemic episodes that might affect child development and school performance is therefore a major challenge in child diabetes care [10-13], especially as poor metabolic control also seems to be associated with learning capacity deficiencies [14].

School performance, as assessed by school marks on leaving compulsory education, may mirror this aspect of the success of diabetes care. In a nationwide population-based study, we therefore examined the school marks of Swedish diabetic children at the time of leaving compulsory education (usually at the age of 16 years). This was done in comparison with all other children and specifically with regard to age at diabetes onset. We linked the prospective Swedish Childhood Diabetes Register (SCDR) with the Swedish School Mark Register, and used the Medical Birth Register (MBR) and the Swedish Educational register in order to adjust for some potential confounders.

\section{Subjects and methods}

Ethical approval The study was approved by the regional research ethics committee in Umeå, which give approval according to the Swedish law on research ethics in line with the principles of the Helsinki declaration and the European Convention on Human Rights and Biomedicine. Approval was also given by the National Board of Health and Welfare. Individual informed consent was given to allow recording of data in the SCDR for research purposes.

Registers used With effect from 1 July 1977 all incident cases of type 1 diabetes in Sweden are reported to a research register, the SCDR. The completeness of the register has varied between 96 and 99\% [15, 16]. From the Swedish School Mark Register information was available on all school marks for children leaving compulsory education in Sweden from 1988 to 2003, i.e. those born between 1973 and 1986 [17]. The children are usually 16 years old when they finish compulsory schooling. The Swedish MBR [18, 19] contains data on pregnancy, delivery and neonatal period for nearly all infants born in Sweden since 1973, with links to information on deaths and emigration. A linkage between the School Mark Register and the MBR was performed and the highest final education level of the mothers, as recorded in the Swedish Educational Register (Statistics, Sweden, available at http:// www.scb.se), was added. Individual identification was removed from the linked register (called 'School MarkMBR Register' in this paper).

Data from the SCDR register were linked to the MBR using the unique personal identification number allocated to each person living in Sweden. Records for some children did not link due to mistakes in the identification number, absence of a record in the MBR or the fact that the child was born outside Sweden. In a final step, this register was linked to the School Mark-MBR Register. This linkage was based on maternal date of birth, infant date of birth, hospital of birth and birthweight (which gives a unique linkage).

School marking system From 1988 to 1997 school marks in Sweden were numerical on a five-level scale. From 1998 the marks became alphabetic, with four levels. The marking systems are not comparable, since the numerical school marks were comparative and standardised using national standard achievement tests in mathematics, English and Swedish, whereas the alphabetical marks are criterionreferenced, with each pupil leaving compulsory education expected to fulfil a criterion for the lowest level. Children diagnosed with a mental disorder attended special schools and their possible marks are not reported to the School Mark Register. Neither are marks for children who attend special schools because of severe hearing or vision disabilities. Some children attending normal compulsory school had special educational needs; these children did not have school marks, but were marked as ' 0 ' in the register.

Statistical analysis The main tool for statistical analysis was the Mantel-Haenszel method with adjustments for four potential confounders: year of birth, maternal age, parity and maternal educational level. The risks were expressed as odds ratios (OR) with 95\% CI estimated by Miettinen's method. Children who died or emigrated before the age of 16 years were excluded from the analysis.

The analysis made a number of comparisons as follows. (1) The rate of not finishing compulsory schooling (usually at the age of 16 years) was studied in children with diabetes and was compared with that of all children. (2) We used the numerical values of school marks during the years 1988 1997 to calculate the mean value of all school marks given to the child. The diabetic children were compared with expected values from the population after stratification for year of birth, maternal age, parity and maternal education. Within each stratum, a $t$ value (with its sign) was determined for the difference between the diabetic children and the population, based on the standard error of the mean of the diabetic children (the population data had a negligible standard error). A series of $t$ values was thus obtained, and their means were tested against 0 with a final $t$ test, labelled $t^{*}$. (3) The distribution of school marks according to the two types described above was compared 
between children with diabetes and all children. Four school subjects were selected for the comparisons: sports, mathematics, English and Swedish. Mathematics, English and Swedish represent the three basic school subjects, which the student must pass in order to enter higher levels of education. Sports was studied because in diabetic children somatic rather than mental capacity may affect performance in this subject, leading to differences between sports and performance in academic subjects. In these studies, the reference group in the analyses was the pass level, represented in the numerical system by the mark 3. (4) Between 1987 and 1997, students in most schools were able to choose between a common and an advanced course in mathematics and in English. We studied the distribution of these choices among children with diabetes and all children.

In most parts of the analysis, the school results were divided into three categories: not passed, passed, and passed with distinction or excellence. The analysis was repeated separately for children aged $<2,2-5,5-10$ and $>10$ years old at the onset of diabetes. These categories represent both age of onset of the disease and its duration, because all were evaluated at the age of 16 years.

The analysis was repeated separately for boys and girls, and comparisons were made with the corresponding sex among all children. A further analysis was made of the numerical scores in order to study correlations between the four selected subjects. This analysis was made with Spearman's rank correlation test.

\section{Results}

Children not finishing ordinary compulsory education Of the 5159 diabetic children recorded in the SDCR and born during the period 1973-1986, 154 (3\%) did not finish their ordinary compulsory education. In the reference population, $36,026(2.8 \%)$ of the $1,294,942$ children failed to do so. The OR for diabetic children not to have finished compulsory schooling, adjusted for year of birth, maternal age, parity and maternal education, was 1.09 (95\% CI, 0.93-1.29). No significant change was noted when excluding children born before 37 weeks' gestational age $(\mathrm{OR}=1.11)$ or children with an Apgar score $<7$ at $5 \mathrm{~min}(\mathrm{OR}=1.09)$. Exclusion of children whose mothers were diagnosed with diabetes during pregnancy did not change the $\mathrm{OR}(\mathrm{OR}=1.10)$.

In the general population, boys were more likely than girls not to finish compulsory schooling $(\mathrm{OR}=1.19,95 \%$ CI 1.16-1.21). The sex of the diabetic child did not significantly influence the OR for not finishing compulsory schooling (boys: 1.03 [95\% CI 0.83-1.29], girls: 1.16 [95\% CI 0.92-1.47]). The two ORs do not differ significantly and neither is significant in itself.
When analysing the effect of age at onset of diabetes (which at the same time means duration of the disease) on not finishing compulsory school, a significant increase in risk was noted only for children who were younger than 2 years at diabetes onset (Table 1).

Mean school mark in all subjects The mean of all numerical school marks (1988-1997) given to an individual was used as an overall estimate of school achievement and the means between diabetic children and other children were compared, adjusting for year of birth, maternal age, parity and maternal education. The mean \pm SD school mark for all diabetic children was $3.15 \pm 0.01$ and the population mean was 3.23 . The mean $t$ value was $-0.24 \pm 0.04$ and the $t^{*}$ value (see Subjects and methods) was $-5.19(p<0.001)$. The small difference is thus highly statistically significant. When groups of different age of onset of diabetes were compared, the lowest mean score was among children diagnosed before the age of 2 years $(2.97 \pm 0.09$ vs $3.08-3.17$ in older age groups), but the difference is not significant. The mean $t$ value for the $<2$ years group was $-0.45 \pm 0.14$ against $-0.22 \pm 0.01$ for the group aged $\geq 2$ years $(t=1.64, p=0.10)$.

School marks for specific subjects When studying the effect of diabetes on school marks in different subjects, we chose to study sports, mathematics, English and Swedish. We made separate analyses for the years 19881997 and 1998-2003, since the methods of marking were not comparable. Figure 1 shows the distribution of the ORs for the four subjects. The correlation between diabetes and poor performance is clear in sports, but less evident in English. In contrast, for mathematics and Swedish, there was an increased risk of a low school mark, but little effect on the probability of getting a high mark. In essence, the graphs for the numerical and the alphabetical score systems resemble each other.

Table 2 shows the results for each of the four subjects, with school marks divided into four groups: none (the child had not attended class enough to get a mark or had required special-needs education), not passed, passed, and passed with distinction or excellence. In all four subjects, the risk of not getting a school mark or not passing was increased

Table 1 Effect of age at onset of diabetes (or duration of diabetes) on not attending compulsory school

\begin{tabular}{lcllc}
\hline & Not attending & Attending & OR & $95 \%$ CI \\
\hline $\begin{array}{l}\text { Population }(n) \\
\text { Diabetes, age at }\end{array}$ & 36,026 & $1,258,916$ & 1.00 & Reference \\
$<2$ & 10 & & & \\
$2-5$ & 15 & 715 & 2.36 & $1.25-4.45$ \\
$5-10$ & 60 & 1,828 & 0.75 & $0.45-1.27$ \\
$>10$ & 69 & 2,324 & 1.18 & $0.91-1.52$ \\
\hline
\end{tabular}


a
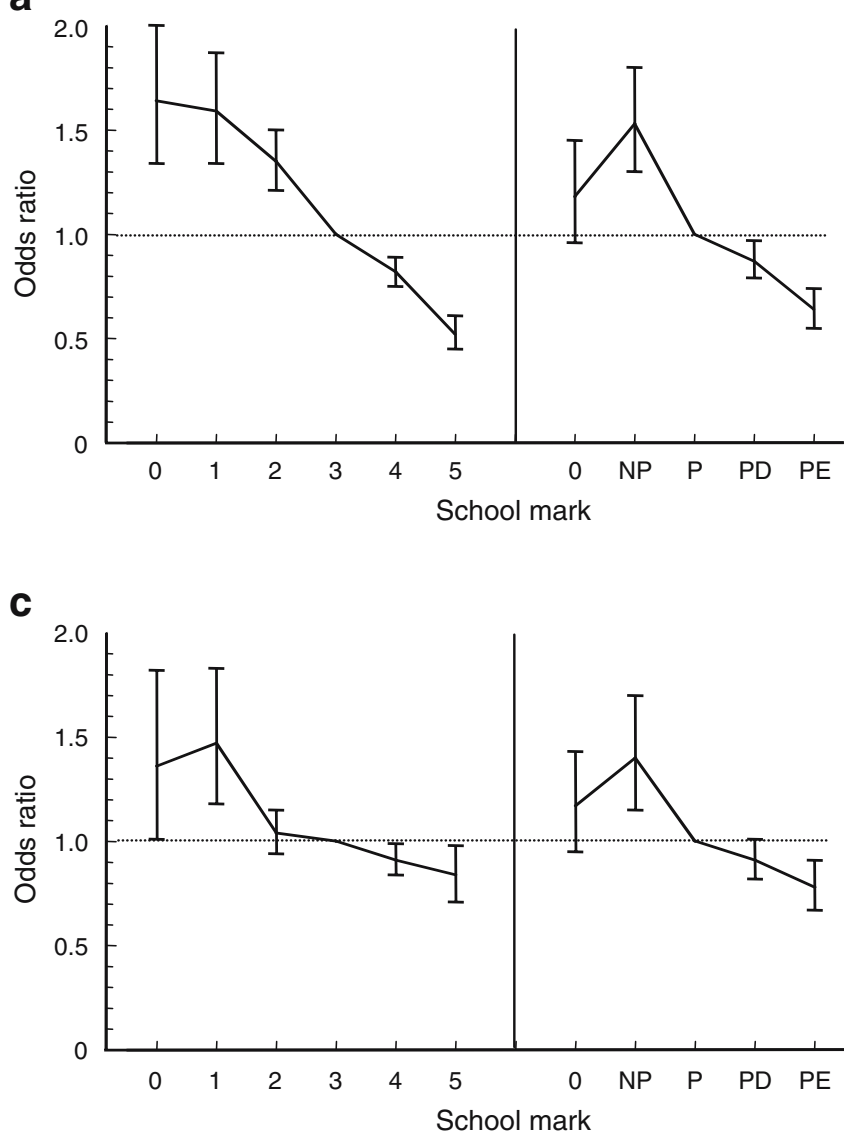

Fig. 1 Odds ratios with 95\% CIs (vertical lines) for children with diabetes having different school marks from other children after adjustment for year of birth, maternal age, parity and maternal education. School marks for sports (a), mathematics (b), English (c) and Swedish (d) are given as numerical marks (1-5) for one period

for a diabetic child. The only estimates that did not reach statistical significance were the estimate for getting no mark (alphabetical marks) and the estimate for not passing (numerical marks) in English, but both were above 1.0.

In two of the subjects (sports and English) the diabetic children had significantly reduced odds of getting a high mark (passed with distinction or excellence), but this was not seen for mathematics and Swedish.

There was no sex-related difference. Among 24 comparisons made, there were two with significantly high ORs for both sexes but with marked differences in estimates (no numerical marks in sports, not passed with alphabetical marks in mathematics). Both differences may be random, however $(z=1.66, p=0.10$ and $z=1.17, p=0.20$, respectively). In one comparison, girls had significantly increased ORs while the ORs for boys were not statistically increased (no numerical marks in mathematics) and in one the opposite was true (not passed, alphabetical marks in English). Neither difference between sexes was statistically significant ( $z=0.47, p=0.36$ and $z=1.42, p=0.15$, respectively).
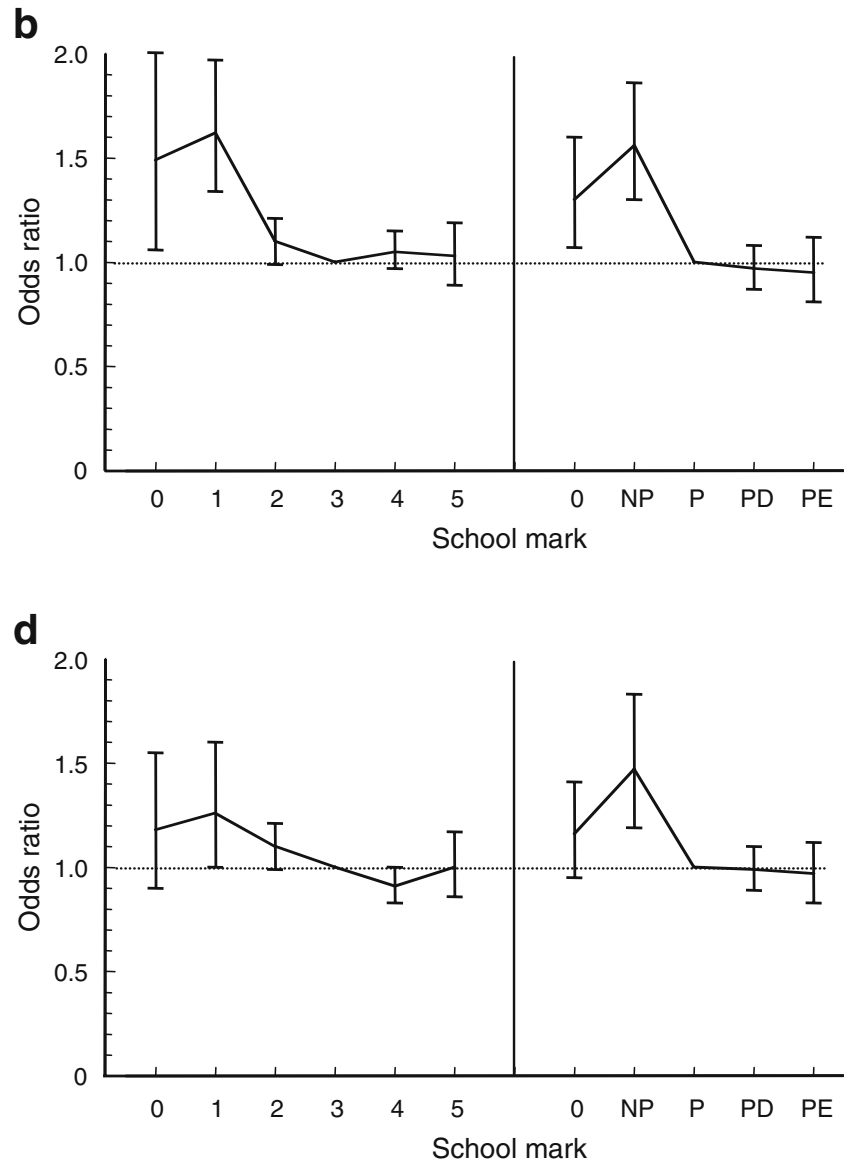

(left-hand side of each figure part), and as alphabetical marks (righthand side of each figure part). $N P$, not passed; $P$, passed; $P D$, passed with distinction; PE, passed with excellence; 0 , child has no school mark in the subject

Figure 2 shows the ORs for the four subjects according to the age at diabetes diagnosis (and therefore also the duration of the disease). In some of the eight graphs, trends can be seen, but there is no general tendency. For English and Swedish, the ORs are high at age of onset $<2$ years, but the CIs are large.

Among diabetic children, there is a relatively strong and statistically highly significant correlation between the numerical scores of the four selected subjects: between sports and the theoretical subjects the Spearman correlation coefficients vary from 0.33 to 0.48 , between the theoretical subjects from 0.59 to 0.68 , with all coefficients being highly statistically significant $(p<0.001)$.

Choice of common or advanced course in Mathematics and English Between 1988 and 1997 Swedish pupils were able to choose between two levels of mathematics and English (common and advanced course). We therefore analysed the effect of having diabetes on these choices. As shown in Table 3, diabetic children had a slightly higher 
Table 2 Odds ratios with 95\% CI, for diabetic children compared with all children, for not passing or for passing with distinction or excellence

\begin{tabular}{|c|c|c|c|c|c|c|c|c|}
\hline \multirow[t]{2}{*}{ Type of marks } & \multicolumn{4}{|c|}{ Numerical marks } & \multicolumn{4}{|c|}{ Alphabetical marks } \\
\hline & Diabetic $(n)$ & Population $(n)$ & OR & $95 \% \mathrm{CI}$ & Diabetic $(n)$ & Population $(n)$ & OR & $95 \% \mathrm{CI}$ \\
\hline \multicolumn{9}{|l|}{ Sports } \\
\hline None & 103 & 15,973 & 1.64 & $1.34-2.01$ & 185 & 42,459 & 1.18 & $0.96-1.45$ \\
\hline NP & 628 & 114,589 & 1.40 & $1.27-1.54$ & 197 & 29,274 & 1.53 & $1.30-1.80$ \\
\hline $\mathrm{P}$ & 1,422 & 354,597 & 1.00 & Reference & 730 & 163,071 & 1.00 & Reference \\
\hline PDE & 1,008 & 334,803 & 0.75 & $0.69-0.81$ & 885 & 245,125 & 0.80 & $0.72-0.89$ \\
\hline \multicolumn{9}{|l|}{ Mathematics } \\
\hline None & 37 & 7,162 & 1.49 & $1.34-2.01$ & 185 & 42,400 & 1.30 & $1.07-1.60$ \\
\hline NP & 782 & 187,957 & 1.15 & $1.05-1.26$ & 145 & 23,580 & 1.56 & $1.30-1.86$ \\
\hline $\mathrm{P}$ & 1,214 & 331,241 & 1.00 & Reference & 977 & 239,999 & 1.0 & Reference \\
\hline PDE & 1,128 & 293,502 & 1.05 & $0.97-1.14$ & 690 & 173,950 & 0.98 & $0.88-1.08$ \\
\hline \multicolumn{9}{|l|}{ English } \\
\hline None & 48 & 9,087 & 1.36 & $1.01-1.82$ & 185 & 42,400 & 1.17 & $0.95-1.43$ \\
\hline NP & 659 & 156,338 & 1.08 & $0.98-1.19$ & 116 & 19,544 & 1.40 & $1.15-1.70$ \\
\hline $\mathrm{P}$ & 1,382 & 351,244 & 1.00 & Reference & 810 & 187,272 & 1.00 & Reference \\
\hline PDE & 1,072 & 303293 & 0.90 & $0.83-0.97$ & 886 & 230,703 & 0.88 & $0.80-0.97$ \\
\hline \multicolumn{9}{|l|}{ Swedish } \\
\hline None & 57 & 12,765 & 1.18 & $0.90-1.55$ & 191 & 46,458 & 1.16 & $0.95-1.41$ \\
\hline NP & 724 & 170,928 & 1.11 & $1.01-1.22$ & 95 & 15,709 & 1.47 & $1.19-1.83$ \\
\hline $\mathrm{P}$ & 1,306 & 337,574 & 1.00 & Reference & 800 & 194,487 & 1.00 & Reference \\
\hline PDE & 1074 & 298,695 & 0.93 & $0.85-1.01$ & 911 & 223,275 & 0.99 & $0.83-1.12$ \\
\hline
\end{tabular}

Values after adjustment for year of birth, maternal age, parity and maternal education. Reference group is children who just passed $(P)$. None means that the child did not attend class often enough to get a mark or had special-needs education.

$N P$, not passed; $P$, just passed; $P D E$, passed with distinction or excellence

tendency to choose the common course, with a clear tendency to higher risk for children with young onset of diabetes. This reduces the differences in scores in mathematics (see above) for this period.

\section{Discussion}

To the best of our knowledge, this is the first nationwide and population-based study of school achievements among children with diabetes with a power to also detect rather small effects and designed to permit adjustments for at least some putative confounders.

We show that Swedish children with type 1 diabetes at onset after 1 July 1977 had different school achievements at the age of 16 years (when leaving compulsory education). A clear effect, in the form of non-completion of normal compulsory schooling, was seen only in children with diabetes onset below 2 years old. There are many reasons why a child does not complete compulsory schooling. He or she may have gone to school abroad, for example. However, the main reason is probably various forms of disability necessitating special schooling.

The mean school mark (for the years with numerical marks) was used as an estimate of the global effect of diabetes on school performance among those children who completed compulsory schooling. Mean school marks in diabetic children were significantly lower than those in all children, but the difference was small. This effect was more marked in children with an onset of diabetes before the age of two years, and therefore a longer disease duration than in children with late onset, but this difference may be random.

Another clear-cut difference was seen in the special study of the choice of common or advanced courses in mathematics and English during the years when this choice was available. For this variable, an effect of the age of onset of the disease and therefore also long disease duration could be seen.

When individual subjects were analysed, the picture was more complex. We compared four groups: (1) children who (even though they finished compulsory schooling) had no mark in the subject; (2) children who did not pass; (3) children who passed; and (4) children who passed with distinction or excellence. There were two reasons for this: the categorisation is reasonably robust and it can also be applied to numerical and alphabetical marks. In general, the ORs agreed for the two score systems. There was no clear tendency towards a difference in effects according to age of onset (and therefore also duration of the disease), but in many cells numbers were low. It should also be noted that the school marks in mathematics and English are compli- 

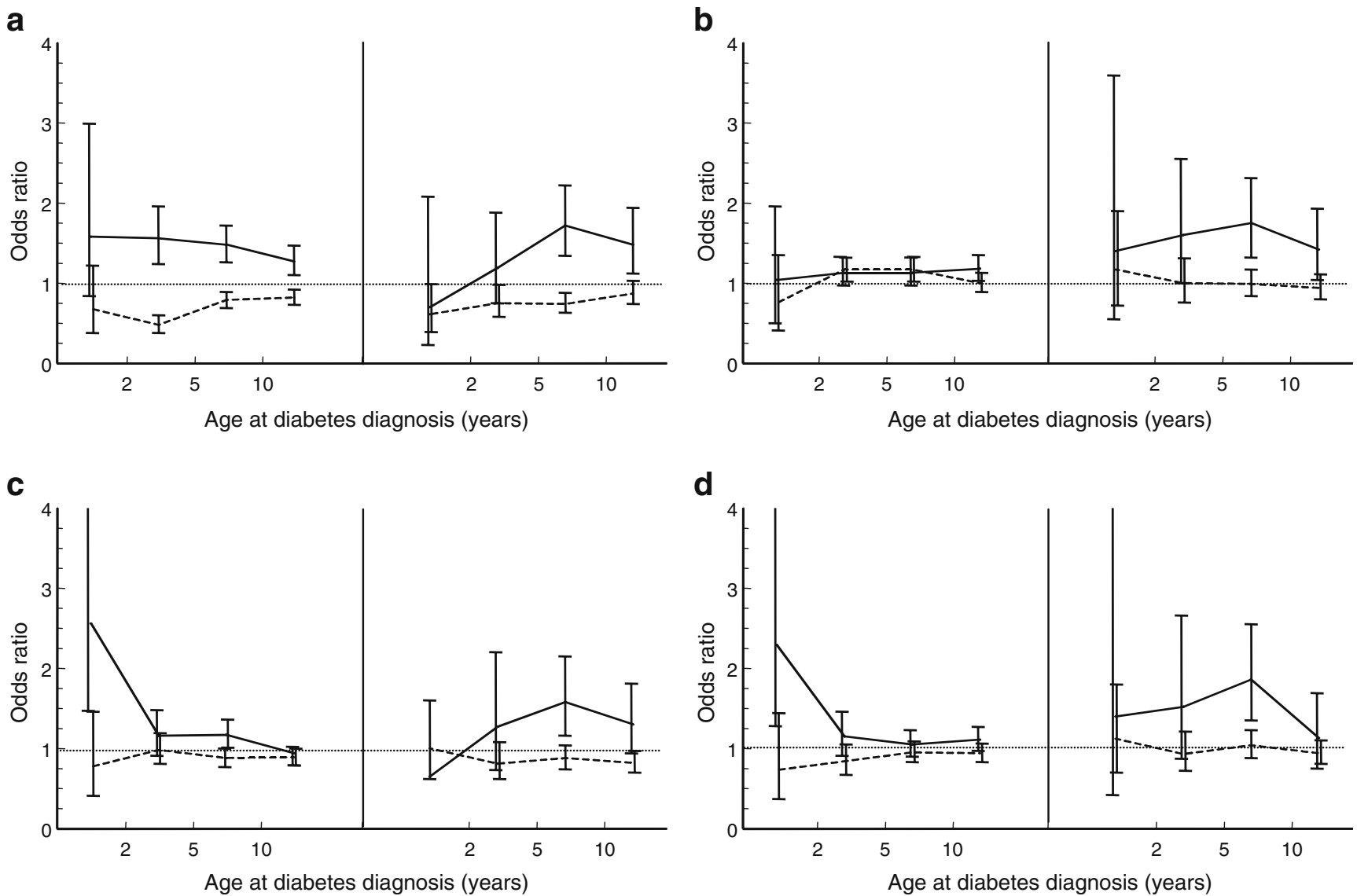

Fig. 2 Odds ratios with $95 \%$ CIs (vertical lines) for children with diabetes not achieving a pass (solid line) or to pass with distinction or excellence (dashed line) in sports (a), mathematics (b), English (c) and Swedish (d). Data are after adjustment for year of birth, maternal

cated by the above-mentioned choice between common and advanced courses.

A large number of studies have been published on the educational and academic performance of diabetic children (recent review in [20]). Most of these studies are small and

d

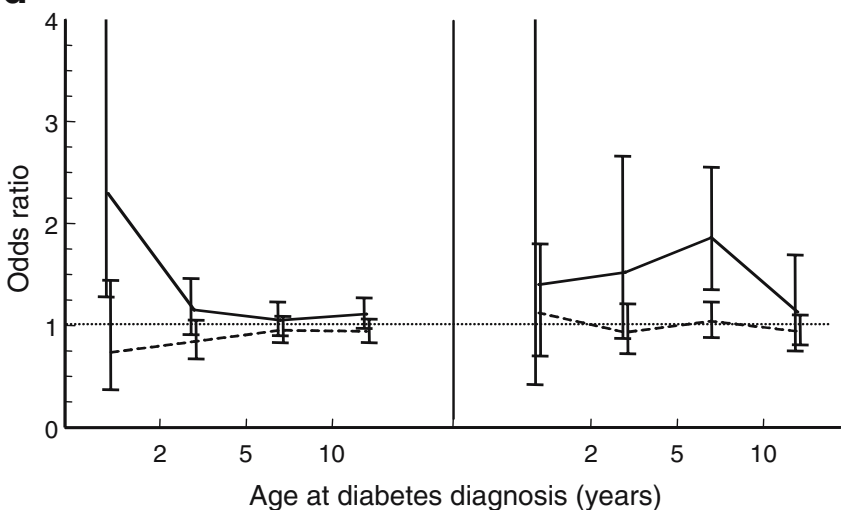

age, parity and maternal education. For the first period a numerical system was used (left-hand side of each figure part), for the second an alphabetic system (right-hand side of each figure part)

not population-based, but on the other hand include formal testing of different aspects of learning capabilities. The above-mentioned review concludes that children with diabetes are more likely to be at an academic disadvantage, which agrees with our findings. Moreover, this review and

Table 3 Effect of age at onset of diabetes on choosing common versus advanced course in mathematics and English in the years 1987-1997

\begin{tabular}{lllll}
\hline & Common & Advanced & OR & 95\% CI \\
\hline $\begin{array}{l}\text { Mathematics } \\
\text { Population }\end{array}$ & 465,967 & 321,163 & 1.00 & Reference \\
$\begin{array}{l}\text { Diabetes patients } \\
\text { All (age at onset, years) }\end{array}$ & 1,714 & 1,266 & 1.08 & $1.00-1.17$ \\
$<2$ & 30 & 30 & 1.65 & $1.01-2.68$ \\
$2-5$ & 233 & 194 & 1.23 & $1.01-1.50$ \\
$5-10$ & 653 & 457 & 1.02 & $0.90-1.16$ \\
$>10$ & 798 & 585 & 1.07 & $0.95-1.19$ \\
English & & & & \\
Population & 562,141 & 216,805 & 1.00 & Reference \\
Diabetes patients & & & \\
All (age at onset, years) & 2,069 & 914 & 1.16 & $1.07-1.26$ \\
$<2$ & 40 & 21 & 1.63 & $0.92-2.80$ \\
$2-5$ & 282 & 151 & 1.47 & $1.20-1.80$ \\
$5-10$ & 784 & 325 & 1.09 & $0.95-1.25$ \\
$>10$ & 963 & 417 & 1.15 & $1.02-1.30$ \\
\hline
\end{tabular}


another that focused on neurocognitive correlates of type 1 diabetes in children [21] concluded that many, but not all papers demonstrate an association between poor cognitive functioning and early onset of diabetes (younger than 5 years). Our study thus confirms, in a large nationwide and well defined population, a global effect of childhoodonset diabetes on educational achievements for some studied variables, especially with very early onset (or long duration) and after adjustment for some putative confounding factors, such as maternal education, maternal age, parity and birth year.

The mechanism behind the association between diabetes and school performance is probably complex and may include permanent brain damage due to early severe episodes of hypoglycaemia [21, 22] or severe ketoacidosis [23], as well as other transient effects on attention, memory, visual-spatial deficits and executive function due to episodes of less severe hypoglycaemia [24, 25], not to mention disease-related psychological effects. The more severe neurocognitive deficits seen in early-onset type 1 diabetes have been attributed both to the sensitivity of the developing brain to hypoglycaemia, and to the difficulty in controlling and detecting low blood glucose in very young children [21]. Unfortunately, the present register study had no access to relevant clinical data, e.g. median $\mathrm{HbA}_{1 \mathrm{c}}$ or the number of ketoacidotic or hypoglycaemic episodes in the children. It should be emphasised that this study, like several others, cannot distinguish between the effect of young age at onset and duration of diabetes. Long-term effects of the disease, as mirrored by correlates of cognitive function deficits with disease duration, may also be associated with visual and verbal memory deficit, as well as reduced motor strength and poor fine motor control [21]. Obviously, the cumulative incidence of both hypoglycaemic and ketoacidotic episodes would be associated with a long disease duration.

It is well known that children's overall performance in school is linked, so that a good mark in one subject will tend to be associated with good marks in other subjects, including sports. In children with diabetes the effects of the disease on different subjects may clearly differ. For instance, both parents and teachers may hesitate to let the child participate in sports with maximum effort due to the risk of hypoglycaemia.

In conclusion, we have established that in Sweden, with its active childhood diabetes care, we have not succeeded in preventing childhood diabetes from affecting the educational achievements of diabetic children. The effects, however, are modest and tend to be more obvious among young-onset patients, which is consistent with other studies. Results can only be generalised to Sweden, and it would be desirable to conduct studies in other countries. Further studies should also focus on whether the effects observed by us have any significant effect on future academic performance and socioeconomic status. Our results also suggest that special clinical attention should be given to patients with the youngest age of onset, and that they should possibly also be given extra support at school.

Acknowledgements This project was supported by grants from the Swedish Research Council (Project no. 07531) and the Västerbotten County Council (to G. Dahlquist), as well as from the K. and A. Wallenberg Foundation (to B. Källén). We also wish to thank the National Board of Health and Welfare for providing data sets. We thank all the paediatricians and nurses at the paediatric clinics in Sweden who participate in registration for the Swedish Childhood Diabetes Study.

Duality of interest Neither of the authors has a duality of interest in connection with this study.

\section{References}

1. Hovind P, Tarnow L, Rossing K et al (2003) Decreasing incidence of severe diabetic microangiopathy in type 1 diabetes. Diabetes Care 26:1258-1264

2. Nordwall M, Bojestig M, Arnqvist HJ, Ludvigsson J (2004) Declining incidence of severe retinopathy and persisting decrease of nephropathy in an unselected population of type 1 diabetesthe Linkoping diabetes complications study. Diabetologia 47:1266-1272

3. Pambianco G, Costacou T, Ellis D, Becker DJ, Klein R, Orchard TJ (2006) The 30-year natural history of type 1 diabetes complications: the Pittsburgh epidemiology of diabetes complications study experience. Diabetes 55:1463-1469

4. Diabetes Control and Complications Trial/Epidemiology of Diabetes Interventions and Complications Study (DCCT/EDIC) Research Group (2005) Intensive diabetes treatment and cardiovascular disease in patients with type 1 diabetes. N Engl J Med 353:2643-2653

5. Rudberg S, Ullman E, Dahlquist G (1993) Relationship between early metabolic control and the development of microalbuminuria: a longitudinal study in children with type 1 (insulin-dependent) diabetes mellitus. Diabetologia 36:1309-1314

6. Svensson M, Eriksson JW, Dahlquist G (2004) Early glycemic control, age at onset, and development of microvascular complications in childhood-onset type 1 diabetes: a population-based study in northern Sweden. Diabetes Care 27:955962

7. Soltesz G (1993) Hypoglycaemia in the diabetic child. Bailliere's Clin Endocrinol Metab 7:741-755

8. Ryan CM, Becker DJ (1999) Hypoglycemia in children with type 1 diabetes mellitus. Risk factors, cognitive function, and management. Endocrinol Metab Clin N Am 28:883-900

9. Fenton CL, Clemons PM, Francis GL (1999) How do the results of the diabetes control and complications trial relate to the practice of pediatrics: who should have intensive management? Pediatr Ann. 28:600-604

10. Drash AL (1993) The child, the adolescent, and the Diabetes Control and Complications Trial. Diabetes Care 16:15151516

11. Bulsara MK, Holman CD, Davis EA, Jones TW (2004) The impact of a decade of changing treatment on rates of severe hypoglycemia in a population-based cohort of children with type 1 diabetes. Diabetes Care 27:2293-2298 
12. Ryan C, Gurtunca N, Becker D (2005) Hypoglycemia: a complication of diabetes therapy in children. Pediatr Clin N Am. 52:1705-1733

13. Kaufman FR, Austin J, Lloyd J, Halvorson M, Carpenter S, Pitukcheewanont P (2002) Characteristics of glycemic control in young children with type 1 diabetes. Pediatr Diabetes 3: 179-183

14. McCarthy AM, Lindgren S, Mengeling MA, Tsalikian E, Engvall J (2003) Factors associated with academic achievement in children with type 1 diabetes. Diabetes Care 26:112-117

15. Dahlquist G, Gustavsson KH, Holmgren G et al (1982) The incidence of diabetes mellitus in Swedish children 0-14 years of age. A prospective study 1977-1980. Acta Paediatr Scand 71:7-14

16. Nyström L, Dahlquist G, Rewers M, Wall S (1990) The Swedish childhood diabetes study - analysis of the temporal variation in diabetes incidence 1978-87. Int J Epidemiol 19:141-146

17. National Agency for Education (2004) Education ResultsNational level. Available at http://www.skolverket.se

18. Cnattingius S, Ericson A, Gunnarskog J, Källén B (1990) A quality study of a medical birth registry. Scand J Soc Med 18:143-148
19. National Board of Health and Welfare (2003) Centre for Epidemiology. The Swedish Medical Birth Register - a summary of content and quality. Available at http://www.sos.se/FULLTEXT/112/2003112-3/2003-112-3.pdf

20. Taras H, Potts-Datema W (2005) Chronic health conditions and student performance at school. J Sch Health 75:255-266

21. Desrocher M, Rovet J (2004) Neurocognitive correlates of type 1 diabetes mellitus in childhood. Child Neuropsychol 10:36-52

22. Flykanaka-Gantenbein C (2004) Hypoglycemia in childhood: long-term effects. Pediatr Endocrinol Rev (Suppl 3):530-536

23. Tsalikian E, Becker DJ, Crumrine PK, Daneman D, Drash AL (1981) Electroencephalographic changes in diabetic ketosis in children with newly and previously diagnosed insulin-dependent diabetes mellitus. J Pediatr 99:355-359

24. Reich JN, Kaspar JC, Puczynski MS et al (1990) Effect of a hypoglycemic episode on neuropsychological functioning in diabetic children. J Clin Exp Neuropsychol 12:613-626

25. Davis EA, Soong SA, Byrne GC, Jones TW (1996) Acute hyperglycaemia impairs cognitive function in children with IDDM. J Pediatr Endocrinol Metab 9:455-461 